\title{
FONTES PARA ESTUDOS DA HISTÓRIA AGRÁRIA NO BRASIL OITOCENTISTA: Caso dos Autos de Medição de Terras*
}

\section{SOURCES FOR STUDIES OF AGRARIAN HISTORY IN BRAZIL OITOCENTISTA: Case of Files of legal documents of Land Measurement}

Francivaldo Alves Nunes**

\begin{abstract}
RESUMO: Os Autos de Medição e Demarcação de Terra constituem para os estudos históricos em importantes fontes manuscritas que reúnem os registros de parte dos processos de revalidação e legitimação de propriedade, previsto no Art. $5^{\circ}$ da Lei $n^{\circ}$. 601, de 18 de setembro de 1850; então chamada Lei de Terras. Em geral, constitui uma documentação judicial, na qual o proprietário ou posseiro deveria provar ser o legítimo dono das terras que então ocupava; além de definir os limites de sua propriedade. Diante das preocupações que envolvem os estudos de História Agrária, diríamos que esta documentação tem o mérito de desvelar as justificativas dos posseiros, sesmeiros e ocupantes de terra quanto à necessidade de medir e demarcar suas terras; os possíveis conflitos envolvendo os requerentes e os confrontantes; as relações conflituosas com as autoridades locais; a importância do papel das testemunhas e a rede de relações pessoais e influências daqueles que pretendiam legitimar a terra; sem contar que desvela os caminhos, em alguns casos, ilícitos, trilhados pelos posseiros para assegurar a concessão do título de terra. Considerando estas diversificadas possibilidades de utilização dos Autos de Medição, nos ocuparemos ainda em destacar que esta documentação constitui importante registro de aspectos da paisagem rural no Brasil; principalmente por que contém descrições minuciosas das propriedades quando da visita dos juizes comissionários para verificação da cultura efetiva e morada habitual, e quando da realização dos trabalhos de medir e demarcar as terras.
\end{abstract}

Palavras-chave: Auto de Medição; História Agrária; Propriedade; Brasil; Século XIX

ABSTRACT: Process Measurement and Demarcation of Land are for historical studies in important manuscript sources that bring together the records of some of the processes of revalidation and legitimating of property provided for in Article 5 of Law no. 601 of September 18, 1850, and then called the Land Law. In general, documentation is a court, in which the owner or leaseholder should prove to be the rightful owner of the land they then occupied, in addition to defining the boundaries of your property. Given the concerns surrounding the study of agrarian history, we would say that this documentation has the merit of revealing the reasons of the squatters, sesmeiro and occupiers of land on the need to measure and demarcate their land, the possible conflicts between the applicants and confrontational; conflictual relations with local authorities, the importance of the role of witnesses and the network of personal relationships and influences of those who wanted to legitimize the land, not to mention that reveals the ways in some cases, illicit trod by squatters to ensure the provision of Title of land. Considering these diverse possibilities of using the Process Measuring, will occupy us further in pointing out that this documentation is an important record of aspects of the countryside in Brazil, mainly because it contains detailed descriptions of the properties during the visit of the judges to verify the commissioners and effective culture habits abode, and upon completion of work to measure and demarcate the land.

Keywords: Process Metering, Agrarian History; Property Brazil; Nineteenth Century.

Nos finais dos anos de 1970 e os que se seguiram foram marcados por uma historiografia muito mais preocupada em analisar as questões a partir de recortes regionais; o que levava a um rompimento com os grandes esquemas explicativos que marcaram momentos anteriores da

Texto inicialmente apresentado no I Encontro Paraense de Estudantes de História, realizado entre os dias 12 e 14 de novembro, no Campus do Guamá, Universidade Federal do Pará, Belém, Pará. Também apresentado no XIV Encontro Regional da ANPUH-RIO, realizado entre 19 e 23 de julho de 2010 na UNIRIO, Rio de Janeiro-RJ. Esta versão foi revisada e ampliada.

** Professor Assistente da Universidade Federal do Pará, atuando na Faculdade de História do Campus Universitário do Tocantins/Cametá. 
historiografia brasileira. ${ }^{1}$ Sobre uma tradição historiográfica associada a grandes esquemas explicativos, citaria os trabalhos de Caio Prado Júnior e a explicação da colonização brasileira enquanto empresa comercial que visava explorar o território brasileiro;2 Maria Silvia de Carvalho Franco, que embora se propusesse a reconstituir as relações comunitárias dos homens livre e pobres de Guaratinguetá, durante o século XIX, percebiam atuação desses grupos como condição concessória do sistema mercantil; 3 e Jacob Gorender que inseriu os trabalhadores livre e pobres no modo de produção escravista colonial como relação de produção subsidiária, denominando este grupo de categoria heterogenia ao conceito de escravismo colonial. ${ }^{4}$

Estas divergências teóricas, ao mesmo tempo em que resultaram numa complexidade do passado rural no Brasil, exigiram uma minuciosa investigação dos objetos de estudos, o que levaria a um contato maior com diversificadas fontes históricas, que em muitos casos não eram consultadas por serem compreendidas como documentos específicos, regionalizados e locais. No caso dos trabalhos que rompiam com os grandes esquemas explicativos e que atuariam na análise de questões a partir de recortes regionais, citaria os estudos de Warren Dean sobre a expansão cafeeira na região de Rio Claro, enquanto resultado da expropriação da terra ${ }^{5}$ e Peter Eisenberg e sua análise sobre a crise econômica dos fazendeiros de açúcar em Pernambuco. ${ }^{6}$

Do ponto de vista da História Agrária, embora a preocupação inicial estivesse voltada, principalmente, aos resultados dos territórios apropriados e do que nele se produziam; a historiografia mais recente demonstrava interesse com o processo de constituição da propriedade rural. Questionava-se sobre as diversas formas de acesso a terra, de legitimação do direito ao território ocupado e seus múltiplos e complexos desdobramentos. Estas questões, ao mesmo tempo em que exigiam outra leitura da documentação produzida no século XIX, atribuem maior valor as fontes produzidas pelo judiciário, a exemplo dos Autos de Medição de Terras. Para os historiadores que se aventuravam pelo mundo rural e cuja preocupação era entender o

\footnotetext{
1 Dentro dessas perspectivas citaríamos ainda: MARTINS, José de Souza. O cativeiro da terra. São Paulo: Hucitec, 1986; FERNANDES, Florestan. A integração do negro na sociedade de classe. São Paulo: Ática, 1978; e CARDOSO, Fernando Henrique. Capitalismo e Escravidão no Brasil Meridional. Rio de Janeiro: Paz e Terra, 1977. 2 PRADO JUNIRO, Caio. Formação do Brasil Contemporâneo. São Paulo: Brasiliense, 1972.

3 FRANCO, Maria Silvia de Carvalho. Homens Livres na Ordem Escravocrata. São Paulo, Kairós, 1983. 4 GORENDER, Jacob. O Escravismo Colonial. São Paulo: Ática, 1985. Terra, 1977.

DEAN, Warren. Rio Claro: um sistema brasileiro de grande lavoura 1820-1920. Rio de Janeiro: Paz e

$6 \quad$ EISENBERG, Peter. Modernização sem mudança. A indústria açucareira em Pernambuco (1840-1910). Rio de Janeiro: Paz e Terra, 1977. Apontamos ainda os estudos de: SILVA, Francisco Carlos Teixeira da. Camponeses e criadores na formação social da miséria (1820-1920). Niterói, UFF, Dissertação de Mestrado, 1981; CASTRO, Hebe Maria Mattos de. Ao sul da história: lavradores pobres na crise do trabalho escravo. São Paulo: Brasiliense, 1986; e MOTTA, Márcia Maria Menendes. Nas Fronteiras do poder: conflito e direito à terra no Brasil do século XIX. Rio de Janeiro: Vício de Leitura / Arquivo do Estado, 1998.
} 
processo de legitimação de posse ou regularização fundiária no século XIX no Brasil, os Autos de Medição se constituíam como fontes primorosas para o entendimento destas questões.

No caso da Lei de Terras, esta se constituiu como um dos elementos centrais da análise do universo rural no século XIX. Desde a suspensão das doações de sesmarias em 1822, 0 Brasil passou por um longo período sem uma legislação específica que regulamentasse 0 acesso a terra. $O$ receio das restrições aos interesses dos latifundiários, presentes nos projetos apresentados por José Bonifácio de Andrada, durante o Primeiro Reinado, e pelo padre Diogo Antonio Feijó, durante o Período Regencial, fizeram com que o grupo dirigente político atuasse no sentido de postergar a implantação de uma legislação agrária. Aprovada em 1850, a Lei de Terras somente foi regulamentada pelo Decreto $n^{0}$. 1318 de 30 de janeiro de 1854 . Neste contexto, não resta duvida que esta legislação seja política. Sua aplicação foi direcionada aos interesses de determinados grupos, em detrimento de outros. As informações contidas nos Autos de Medição revelam algumas dessas manobras políticas. 0 próprio Regulamento de 1854, como é conhecido o decreto que regulamentou a Lei de Terras, e que instituiu e definiu os Autos de Medição, é interpretado como decreto caracterizado pelo grande número de brechas a aplicação da Lei de Terras, o que para alguns historiadores redirecionou muitos dos dispositivos da lei.?.

\footnotetext{
7 Para uma leitura sobre a Lei de Terra, no entanto, com diferentes perspectivas, cito os estudos de: GUIMARÃES, Alberto Passos. Quatro séculos de latifúndio. 6. ed. Rio de Janeiro: Paz e Terra, 1989; COSTA, Emília Viotti. Da monarquia à república: momentos decisivos. 7. ed. São Paulo: Fundação Editora da Unesp, 1999; MARTINS, José de Souza. O cativeiro da terra. São Paulo: Hucitec, 1986; CARVALHO, José Murilo de. A modernização frustrada: a política de terras no Império. Revista Brasileira de História, São Paulo, n. 1, março 1981, pp. 39-57; 1998. SILVA, Ligia Osório. Terras devolutas e latifúndio: efeitos da lei de 1850. Campinas-SP: Editora da UNICAMP, 2008; e MOTTA, Márcia Maria Menendes. Nas Fronteiras do poder: conflito e direito à terra no Brasil do século XIX. Rio de Janeiro: Vício de Leitura / Arquivo do Estado, 1998.

$8 \quad$ Produzido pela Repartição de Terras Públicas da Província do Pará e atualmente sob a guarda do ITERPA, Instituto de Terras do Pará, refere-se ao Auto de Medição do sítio de Maria Sabina da Conceição, localizado no município de Belém, capital da província do Pará e datado de 10 de janeiro de 1860.
} 


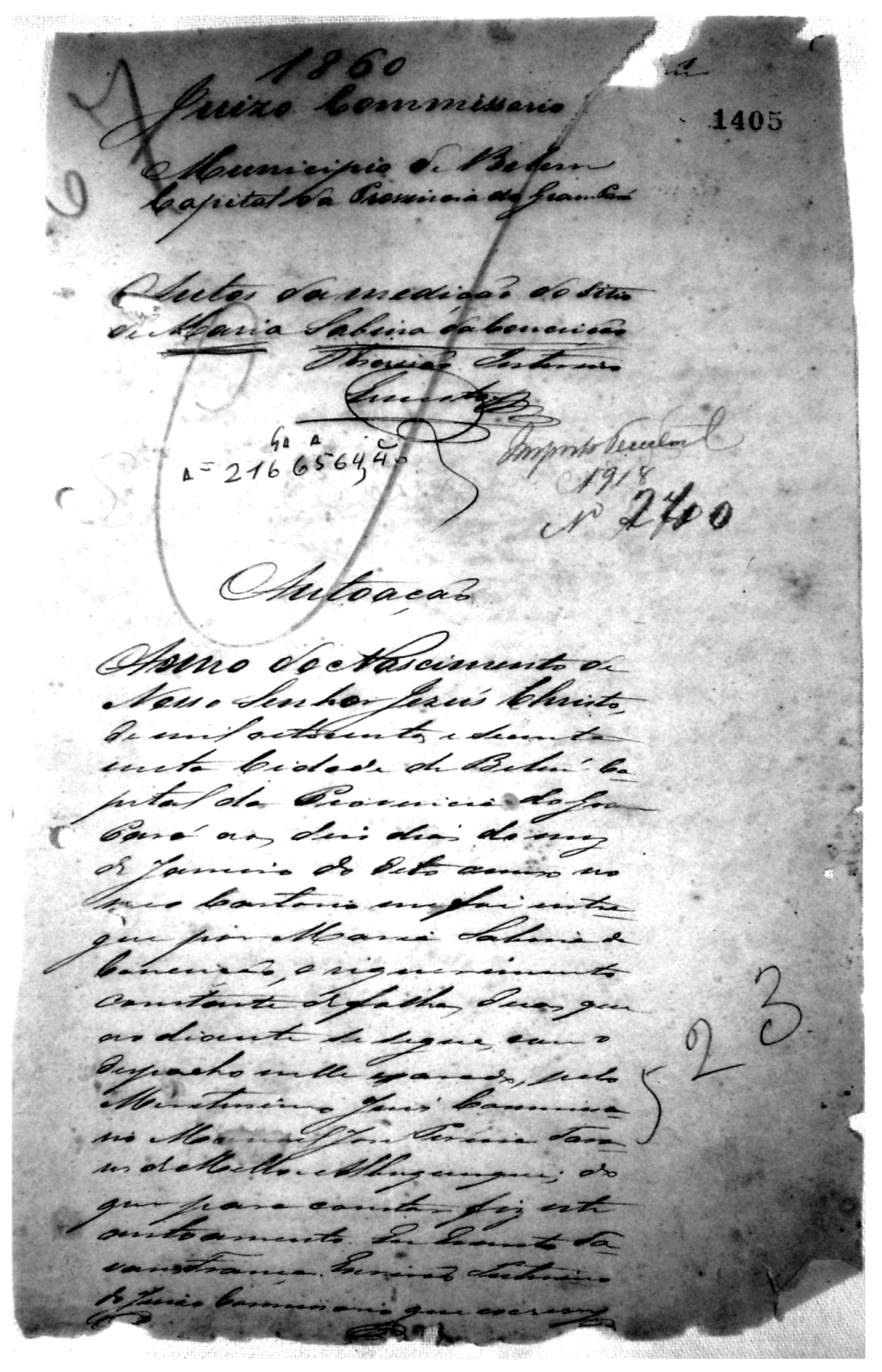

Os Autos de Medição, conforme apontamos faziam parte dos mecanismos propostos no Decreto $n^{0} .1 .318$ de 30 de janeiro de 1854. Constituído de 108 artigos, divididos em 9 capítulos que especificavam os dispositivos da Lei de Terra, o Regulamento tratava da criação da Repartição Geral de Terras Públicas e das competências de seus funcionários; do processo de medições das terras públicas, especificando quais seriam as "terras devolutas", das competências dos inspetores e dos agrimensores nas mensurações e os caminhos burocráticos a serem percorridos pelos proprietários ou posseiros que se sentissem prejudicados com tais medições; especificava as terras e os títulos sujeitos a legitimação e revalidação, sendo tratados ainda os poderes de decisões dos presidentes da província, sobre esta questão, assim como as competências do juiz comissário e o seu papel nas medições e nos litígios; discorria sobre a possibilidade de se revalidar as concessões de datas e sesmarias; destacava as normas de 
venda das terras públicas, a situação das terras reservadas ao aldeamento de indígenas, a logradouros públicos das futuras povoações, estradas e daquelas destinadas a construção naval; tratava, ainda, das terras devolutas situadas nos limites do Império com países vizinhos, destinando uma faixa de 10 léguas (66 quilômetros) nos limites nacionais, sendo nessas condições, próprias para o estabelecimento de colônias militares e civis. O Regulamento de 1854 fazia referência, ainda, a conservação das terras devolutas e dos seus responsáveis e das penas aplicadas aos "infratores" que fossem ocupá-las "ilegalmente". Todos esses dispositivos, direta ou indiretamente, atribuía um importância ao processo de legitimação de terra, dos quais os Autos de Medição estão relacionados.

Quanto ao momento inicial de construção destes Autos, diríamos que estava associado à aplicação do instituto jurídico da época que previa a legitimação e revalidação das propriedades no país, marcado agora pela descentralização do processo de regularização da estrutura fundiária. $O$ poder de comando das atividades de legitimações, medições e titulação de terras, conforme previa a legislação, foi delegado às Repartições de Terras Públicas nas províncias, que estavam submetidas ao Ministério da Agricultura. Além de atuar nos trabalhos de medições das áreas de particulares, de prestar informações sobre os terrenos públicos e de promover os registros das terras legitimadas, a Repartição de Terras Públicas também era responsável pela colonização das terras do governo por estrangeiros e nacionais. Estas atribuições se somavam ainda a perspectiva de que este órgão se tornasse referência aos que buscavam regularizar suas posses de terra. Nesse caso, era na Repartição de Terras Públicas que os posseiros deveriam solicitar a legitimação de sua terra e aguardar a emissão do título de proprietário.

Conforme legislação imperial estavam sujeitas ao processo de legitimação, as terras que se achassem em poder do primeiro ocupante e que não tivesse outro título senão a sua ocupação; e ainda as posses encontradas em poder de um segundo ocupante, desde que este não tivesse adquirido a propriedade por título legítimo. Estavam também inclusas, as posses adquiridas por compra ou doação em que os impostos de transferência de bens de raiz tivessem sido pagos após a publicação do Decreto $n^{0}$. 1.318, de 30 de janeiro de 1854, que, conforme apontamos regulamentava a execução da Lei de Terras de 1850. No caso específico das revalidações, estas faziam referências às sesmarias ou outras concessões do governo imperial e provincial, que se encontrassem ainda sob o domínio dos primeiros sesmeiros ou concessionários; desde que estivessem cultivadas ou com princípio de cultura e moradia habitual, e que não tivessem sido medidas e demarcadas. 
Estava sob a responsabilidade dos presidentes de província a aplicação de ordenações aos juízes de direito, juízes municipais, delegados, subdelegados e juízes de paz quanto às informações sobre a existência ou não em suas comarcas, termos e distritos, de posses sujeitas à legitimação, e de sesmarias ou outras concessões que necessitassem de revalidação. Obtidas as necessárias informações, os presidentes de províncias nomeavam para cada um dos municípios um juiz comissionário de medição. No caso da administração provincial, esta também tinha a tarefa de definir o prazo em que as terras deveriam ser medidas e demarcadas. Datas que, quase sempre, levavam em consideração as circunstâncias de cada município e o maior ou menor número de posses existentes nas municipalidades. Nesse caso, embora ficasse sob a responsabilidade do poder público o levantamento das terras a serem revalidadas e legitimadas, o início do processo de medição e demarcação, davam-se mediante requerimento do ocupante. Neste requerimento o proprietário designava o lugar em que se situava a propriedade e os seus confrontantes. Requerida a medição, o juiz comissionário, verificando a circunstância da cultura efetiva e morada habitual, marcava a data de início dos trabalhos; sendo que as tarefas de medir e demarcar as terras eram antecedidos pela publicidade e convocação dos confrontantes quanto aos dias em que esses trabalhos seriam realizados. ${ }^{9}$

Estudos contemporâneos de História Agrária têm destacado o uso dos Autos de Medição sobre diferentes perspectivas. Márcia Motta ao analisar a relação entre 0 direito e 0 conflito agrário no século XIX, tem se utilizado desta documentação para desconstruir a visão passiva que a historiografia consagrou sobre os lavradores pobres. A preocupação central desta historiadora é mostrar que a legislação sobre terras construída no século XIX apresentava brechas à inserção camponesa e que não foram apenas os grandes fazendeiros que se

$9 \quad$ Estas recomendações estavam estabelecidas nos artigos $7^{\circ}, 8^{\circ}$ e $9^{\circ}$, sobre os quais: "O Governo marcará os prazos dentro dos quais deverão ser medidas as terras adquiridas por posses ou por sesmarias, ou outras concessões, que estejam por medir, assim como designará e instruirá as pessoas que devam fazer a medição, atendendo às circunstâncias de cada Província, Comarca e Município, e podendo prorrogar os prazos marcados, quando o julgar conveniente, por medida geral que compreenda todos os possuidores da mesma Província, Comarca e Município, onde a prorrogação convier"; "Os possuidores que deixarem de proceder à medição nos prazos marcados pelo Governo serão reputados caídos em comisso, e perderão por isso o direito que tenham a ser preenchidos das terras concedidas por seus títulos, ou, por favor, da presente Lei, conservando-o somente para serem mantidos na posse do terreno que ocuparem com efetiva cultura, havendo-se por devoluto o que se achar inculto"; e "Não obstante os prazos que forem marcados, o Governo mandará proceder à medição das terras devolutas, respeitando-se no ato da medição os limites das concessões e posses que se acharem nas circunstâncias dos artigos $4^{\circ}$ e $5^{\circ}$. Qualquer oposição que haja da parte dos possuidores não impedirá a medição; mas, ultimada esta, se continuará vista aos opoentes para deduzirem seus embargos em termo breve". Legislação completa disponível em: SOUZA, Donato Cardoso de. O estrangeiro e as terras brasileiras. Belém, CEJUP, 1982, p. 95. 
utilizaram da Lei para garantir a posse da terra; no caso dos pequenos posseiros, estes também se valeram da mesma em seus litígios. Assim, privilegiando o conflito agrário, a autora se utiliza dos Autos de Medição para resgatar a esfera de lutas de pequenos posseiros, mostrando que estas lutas não podem ser analisadas apenas no âmbito de grandes conflitos agrários, mas também em atividades isoladas de contestação ao poder do grande latifundiário. Márcia Motta defende que os efeitos da legislação construída em torno da propriedade e que tem nos Auto de Medição a sua aplicabilidade, não são frutos de um fator unilateral, mas resultado de toda uma dinâmica de apropriação territorial. ${ }^{10}$

Helen Ortiz considerando os Autos de Medição como fontes significativamente importantes para compreender como se efetivou a aplicação do instituto jurídico da Lei de Terra na região de Soledade, no Norte Rio Grande do Sul, se propõe a conhecer as origens da ocupação territorial da região, as formas de acesso, uso e exploração da terra; as relações vividas entre proprietários e não proprietários e os possíveis conflitos de classes e de interesses daí decorrentes. Nesse aspecto, os Autos de Medição foram analisados na perspectiva de se compreender a estrutura agrária da região, levando em conta as contradições presentes na sociedade e as relações de trabalho, o tipo de mão-de-obra e as relações mercantis que configuraram o território do Norte do Rio Grande do Sul. ${ }^{11}$

As apropriações de terras ao longo do Segundo Reinado em uma região específica do Brasil, no caso do Vale do Taquari no Rio Grande do Sul, foi objeto de estudo de Cristiano Christillino. No caso, os Autos de Medição foram analisados com a perspectiva de desvelar as irregularidades presentes no processo de expropriações de terras praticadas contra os lavradores nacionais que se utilizavam das terras de florestas. No entanto, a expropriação e as possíveis fraudes, identificadas nestes autos, não foram estudadas como um processo mecânico, mas como instrumentos construídos a partir da legislação sobre a propriedade; nesse caso os Autos de Medição não apenas revelaram as estratégias fraudulentas construídas pelos posseiros para assegurar o domínio sobre a terra, mais também revelou aspectos importantes quanto à constituição das redes de clientela e as influências dos grandes proprietários junto às instâncias de poder no Brasil do Segundo Reinado (CHRISTILLINO, 2004).

Identificar a constituição da paisagem agrária na província do Pará durante as duas ultimas décadas do império foi à perspectiva que trabalhamos, quando se analisou os Autos de Medição de Terras. Esta documentação revelou aspectos importantes das grandes propriedades

10 MOTTA, Márcia Maria Menendes. Nas Fronteiras do poder: conflito e direito à terra no Brasil do século XIX. Rio de Janeiro: Vício de Leitura / Arquivo do Estado, 1998.

11 ORTIZ, Helen Scorsatto. O banquete dos ausentes: A Lei de Terras e a formação do latifúndio no norte do Rio Grande do Sul (Soledade - 1850-1889). Passo Fundo, UPS, Dissertação de Mestrado, 2006. 
rurais da região, a exemplo da dimensão territorial dessas propriedades, as características das áreas de cultivo, os tipos de plantio, os produtos que resultavam das atividades extrativistas, as construções e os tipos de mão-de-obra nessas propriedades; características que foram importantes para se entender os interesses desses grandes proprietários de terras nos projetos de colonização pensados para a Amazônia. ${ }^{12}$

Atualmente, os Autos de Medição são encontrados nos arquivos públicos e arquivos dos institutos de regularização fundiária. Nas regiões marcadas por um histórico de adulterações de títulos de propriedade, estes documentos têm sido alvos de falsificadores, e em outros casos são extraviados propositalmente; o que leva as instituições que têm a sua guarda a dificultar 0 acesso, principalmente autorizar a reprodução de cópia desta documentação. No caso da sua estruturação, quatro situações marcavam o formato dos Autos de Medição: a primeira, caracterizada pelo momento inicial do processo, quando o posseiro solicitava a regularização de suas terras, a segunda quando o juiz comissionário atestava a utilização da propriedade, identificando o seu uso associado à cultura efetiva e morada habitual, a terceira quando havia a convocação dos possíveis interessados com os trabalhos de medição de terra, no caso, os confrontantes da propriedade a ser medida e demarcada, e por ultimo, situaria os trabalhos de medição, caracterizado pela definição dos limites da propriedade.

Diante das preocupações que envolvem a História Agrária, diríamos que os Autos de Medição têm o mérito de desvelar as justificativas dos posseiros, sesmeiros e ocupantes quanto à necessidade de medir e demarcar suas terras; os possíveis conflitos envolvendo os requerentes e os confrontantes; as relações conflituosas com as autoridades locais; a importância do papel das testemunhas e a rede de relações pessoais e influência daqueles que pretendiam legitimar a terra; sem contar que esta documentação desvela os caminhos, em alguns casos, ilícitos, trilhados pelos posseiros para assegurar a concessão do título de terra. Esta documentação se constitui ainda como um importante registro de aspectos da paisagem rural no Brasil, principalmente por que contém descrições minuciosas das propriedades quando da visita dos juízes comissionários para verificação da cultura efetiva e morada habitual e quando da realização dos trabalhos de medir e demarcar as terras.

12 NUNES, Francivaldo A. Benevides: uma experiência de colonização na Amazônia do século XIX. Rio de Janeiro, Editora Corifeu, 2009; e NUNES, Francivaldo A. A Semente da Colonização: Um estudo sobre a Colônia Agrícola Benevides (Pará, 1870-1889). Belém, UFPA, Dissertação de Mestrado, 2008. 


\section{Bibliografia}

1. CARDOSO, Fernando Henrique. Capitalismo e Escravidão no Brasil Meridional. Rio de Janeiro: Paz e Terra, 1977.

2. CARVALHO, José Murilo de. A modernização frustrada: a política de terras no Império. Revista Brasileira de História, São Paulo, n. 1, março 1981, pp. 39-57.

3. CASTRO, Hebe Maria Mattos de. Ao sul da história: lavradores pobres na crise do trabalho escravo. São Paulo: Brasiliense, 1986.

4. COSTA, Emília Viotti. Da monarquia à república: momentos decisivos. 7. ed. São Paulo: Fundação Editora da Unesp, 1999.

5. CHRISTILLINO, Cristiano. Estranhos em seu próprio chão: o processo de apropriações e expropriações de terras na Província de São Pedro Do Rio Grande do Sul (o Vale do Taquari no período de 1840-1889). São Leopoldo, UNISINOS, Dissertação de Mestrado, 2004.

6. DEAN, Warren. Rio Claro: um sistema brasileiro de grande lavoura 1820-1920. Rio de Janeiro: Paz e Terra, 1977.

7. EISENBERG, Peter. Modernização sem mudança. A indústria açucareira em Pernambuco (1840-1910). Rio de Janeiro: Paz e Terra, 1977.

8. FERNANDES, Florestan. A integração do negro na sociedade de classe. São Paulo: Ática, 1978.

9. FRANCO, Maria Silvia de Carvalho. Homens Livres na Ordem Escravocrata. São Paulo, Kairós, 1983.

10. GORENDER, Jacob. O Escravismo Colonial. São Paulo: Ática, 1985.

11. GUIMARÃES, Alberto Passos. Quatro séculos de latifúndio. 6. ed. Rio de Janeiro: Paz e Terra, 1989.

12. MARTINS, José de Souza. O cativeiro da terra. São Paulo: Hucitec, 1986.

13. MOTTA, Márcia Maria Menendes. Nas Fronteiras do poder: conflito e direito à terra no Brasil do século XIX. Rio de Janeiro: Vício de Leitura / Arquivo do Estado, 1998.

14. NUNES, Francivaldo A. Benevides: uma experiência de colonização na Amazônia do século XIX. Rio de Janeiro, Editora Corifeu, 2009.

15. NUNES, Francivaldo A. A Semente da Colonização: Um estudo sobre a Colônia Agrícola Benevides (Pará, 1870-1889). Belém, UFPA, Dissertação de Mestrado, 2008.

16. ORTIZ, Helen Scorsatto. $O$ banquete dos ausentes: A Lei de Terras e a formação do latifúndio no norte do Rio Grande do Sul (Soledade - 1850-1889). Passo Fundo, UPS, Dissertação de Mestrado, 2006.

17. OSÓRIO, Helen. Estancieiros, lavradores e comerciantes na constituição da estremadura portuguesa na América: Rio Grande de São Pedro, 1737-1822. Niterói: UFF, Tese de Doutorado, 1999.

18. SILVA, Ligia Osório. Terras devolutas e latifúndio: efeitos da lei de 1850. Campinas-SP: Editora da UNICAMP, 2008.

19. PRADO JUNIOR, Caio. Formação do Brasil Contemporâneo. São Paulo: Brasiliense, 1972.

20. SILVA, Francisco Carlos Teixeira da. Camponeses e criadores na formação social da miséria (1820-1920). Niterói, UFF, Dissertação de Mestrado, 1981.

21. SOUZA, Donato Cardoso de. O estrangeiro e as terras brasileiras. Belém, CEJUP, 1982.

\section{Artigo recebido em: 21/01/2011 \\ Aprovado em: 04/03/2011}

